\title{
COMPOSIÇÃO E DINÂMICA DA BIOMASSA AÉREA APÓS A QUEIMA EM SAVANA GRAMÍNEO-LENHOSA NO PANTANAL ${ }^{1}$
}

\author{
EVALDO LUIS CARDOSO², SANDRA MARA ARAÚJO CRISPIM², \\ CRISTINA APARECIDA G. RODRIGUES ${ }^{3}$ e WALDOMIRO BARIONI JÚNIOR ${ }^{4}$
}

\begin{abstract}
RESUMO - O objetivo deste estudo foi avaliar a composição e dinâmica da biomassa aérea após a queima de uma savana gramíneo-lenhosa no Pantanal. Foram coletados dados mensais de frequiência de espécies, biomassa aérea e cobertura do solo durante 11 meses em uma área com queima (CQ) e outra sem queima (SQ), ambas sem pastejo. A queima reduziu a freqüência das gramíneas predominantes e condicionou aumento no número de espécies dicotiledôneas e ciperáceas. A produção de biomassa aérea total foi inferior na área com queima, embora a tendência de incremento tenha sido semelhante nas duas áreas. A produção de biomassa morta foi muito afetada pela queima, cuja produção, 11 meses após, representou aproximadamente $25 \%$ da obtida na área sem queima. A cobertura do solo foi inferior na área com queima e somente no quarto mês assemelhou-se à área sem queima.
\end{abstract}

Termos para indexação: queimada, cobertura do solo, pastagem nativa, gramíneas, espécies, dicotiledôneas, ciperáceas, manejo de pastagem.

\section{COMPOSITION AND AERIAL BIOMASS DYNAMICS AFTER BURNING OF A GRASSY-WOODY SAVANNA IN THE PANTANAL WETLANDS}

\begin{abstract}
The purpose of this work was to evaluate composition and aerial biomass dynamics after burning of a grassy-woody savanna in the Pantanal wetlands, Brazil. During 11 months, data on species frequency, aerial biomass and soil cover were collected in an area with burning (WB) and another free of burning (FB), both not grazed. Burning reduced the frequency of the most predominant grasses and increased the number of dicotyledons and cyperaceae species. The production of total aerial biomass was lower in the WB area, despite an increase tendency that was similar in both areas. Litter production was strongly affected by burnings. After 11 months its production was approximately $25 \%$ of the production exhibited by the FB area. Soil cover was also lower in the WB and only after four months it was similar to the FB area.
\end{abstract}

Index terms: burning, mulching, natural pastures, grasses, species, dicotyledonons, cyperaceae, grassland management.

${ }^{1}$ Aceito para publicação em 27 de janeiro de 2000.

Pesquisa parcialmente financiada pelo Conselho Estadual de Ciência e Tecnologia (CECITEC), Secretaria de Estado de Planejamento e de Ciência e Tecnologia (SEPLAN-MS).

${ }^{2}$ Eng. Agrôn., M.Sc., Embrapa-Centro de Pesquisa Agropecuária do Pantanal (CPAP), Caixa Postal 109, CEP 79320-900 Corumbá, MS.

E-mail: evaldo@cpap.embrapa.br; scrispim@cpap.embrapa.br

${ }^{3}$ Zoot., M.Sc., Embrapa-CPAP. E-mail: crisagr@cpap.embrapa.br

${ }^{4}$ Estatístico, M.Sc., Embrapa-Centro Nacional de Pesquisa de Suínos e Aves, Caixa Postal 21, CEP 89700-000 Concórdia, SC. E-mail: barioni@cnpsa.embrapa.br

\section{INTRODUÇÃO}

O fogo constitui fator ecológico de significativa importância em diversos sistemas de pastagens; em particular naqueles localizados em regiões tropicais e subtropicais com estacionalidade hídrica marcante, como por exemplo as savanas africanas e americanas (Frangi et al., 1980).

No Pantanal, as pastagens nativas constituem, praticamente, a base da alimentação do rebanho de aproximadamente 3,8 milhões de bovinos anelorados, 
e estão sujeitas à queda em quantidade e qualidade da forragem na época seca, e redução da área disponível para pastejo nos períodos de inundação (Embrapa, 1993). A queima das pastagens nativas é realizada anualmente, porém, sua utilização se faz de forma seletiva e localizada, procurando eliminar ou conter a expansão de espécies indesejáveis e promover o rebrote das forrageiras de baixa aceitabilidade, sendo comumente queimadas as áreas de caronal (Elyonurus muticus), de capim-furabucho (Paspalum carinatum e $P$. lineare), de capimrabo-de-burro (Andropogon bicornis) e cerrados ralos (Pott, 1982).

Entre as diversas razões apresentadas para justificar a utilização da queima como opção de manejo das savanas e campos naturais durante a época de seca, destaca-se a necessidade de obtenção de forragem fresca e palatável para o gado em períodos com escassez desse tipo de alimento (Coutinho et al., 1982). Os efeitos da queima na biomassa são qualitativamente semelhantes onde quer que ocorra, entretanto, a resposta das plantas varia significativamente, tanto entre comunidades como dentro de uma mesma comunidade (Klink \& Solbrig, 1996). Segundo Batmanian (1983), seus efeitos podem variar conforme a época e freqüência da queimada, tipo de solo e clima da região.

Blydenstein (1963) e San José \& Medina (1975) observaram nas savanas venezuelanas que as queimadas provocavam aumento ou aceleração da produção primária, atribuído ao efeito adubador das cinzas, à destruição do "mulch" ou à elevação de temperatura do solo. Segundo Valentine (1990), a maior produção de forragem verificada em áreas submetidas à queima pode ser atribuída à eliminação da macega acumulada que pode dificultar o novo crescimento das plantas, pela menor incidência de luz nas gemas basais. Segundo Mattos (1970) o uso do fogo melhora a qualidade da forragem e aumenta a produtividade após a queima, resultando em grandes benefícios para os animais, o que por si só seria suficiente para justificar o uso dessa prática no manejo dos campos e pastagens naturais.

Por sua vez, menor disponibilidade de forragem e redução na produção total de matéria seca nos meses subseqüentes à queima também foi relatada por alguns autores (Cesar, 1980; Fontaneli \& Jacques,
1988; Neiva,1990; Fontaneli et al., 1994). De acordo com Pereira \& Peres (1985), pastagens naturais dos cerrados, quando queimadas, têm restauração muito rápida nos primeiros dias de chuva subseqüente, mas três a cinco meses depois as pastagens não-queimadas apresentam maior suporte de pastejo. Indicando, segundo os autores, que parte dos nutrientes acumulados nas cinzas é imobilizada novamente pelas plantas e parte se perde por lixiviação ou erosão.

Embora a queima das pastagens nativas seja uma questão polêmica, sua utilização como alternativa de manejo é uma realidade.

Este trabalho teve como objetivo avaliar o efeito de uma queimada sobre a composição e dinâmica da biomassa aérea do estrato herbáceo de uma savana gramíneo-lenhosa sem pastejo no Pantanal.

\section{MATERIAL E MÉTODOS}

O trabalho foi conduzido no campo experimental da Embrapa-Centro de Pesquisa Agropecuária do Pantanal, sub-região da Nhecolândia, localizada na latitude $18^{\circ} 59^{\prime} \mathrm{S}$ e longitude $56^{\circ} 37^{\prime} \mathrm{W}$, Pantanal Sul-Mato-Grossense, no período de outubro de 1995 a agosto de 1996.

De acordo com a classificação climática de Köppen, o Pantanal possui clima tropical subúmido (Aw), com média em torno de $1.100 \mathrm{~mm}$ anuais de chuva, com estação chuvosa de outubro a março e relativamente seca de abril a setembro. A temperatura média anual é de $26^{\circ} \mathrm{C}$, podendo ocorrer geada esporádica (Cadavid García, 1984). Os dados de precipitação pluvial são apresentados na Fig. 1 (Boletim Agrometeorológico, 1997).

O estudo foi desenvolvido em savana gramíneo-lenhosa (Abdon et al., 1998), sujeita à inundação. O relevo é plano e o solo classificado como Areia Quartzosa Hidromórfica Distrófica, com o seguinte resultado de análise química de amostras coletadas na camada de $0-20 \mathrm{~cm}$ : $\mathrm{pH}$ (em água), 5,4; $\mathrm{P}, 1,2 \mathrm{mg} \mathrm{dm}^{-3} ; \mathrm{Ca}+\mathrm{Mg}, 3,2 \mathrm{mmol}_{\mathrm{c}} \mathrm{dm}^{-3} ; \mathrm{K}$, $0,99 \mathrm{mmol}_{\mathrm{c}} \mathrm{dm}^{-3} \mathrm{e} \mathrm{Al}, 0 \mathrm{mmol}_{\mathrm{c}} \mathrm{dm}^{-3}$.

Duas áreas adjacentes de $100 \mathrm{~m}$ x $40 \mathrm{~m}$, devidamente aceiradas e cercadas com fios de arame para impedir o pastejo, corresponderam, respectivamente, aos tratamentos testemunha (sem queima - SQ) e com queima (CQ). Em cada área, foram demarcadas 10 parcelas de $20 \mathrm{~m} \mathrm{x}$ $20 \mathrm{~m}$, dentro das quais foram feitas as avaliações mensais. Em setembro de 1995, logo após as primeiras chuvas, efetuou-se a queima de uma das áreas, e 30 dias após, iniciaram-se as avaliações mensais realizadas durante os 11 meses subseqüentes. 


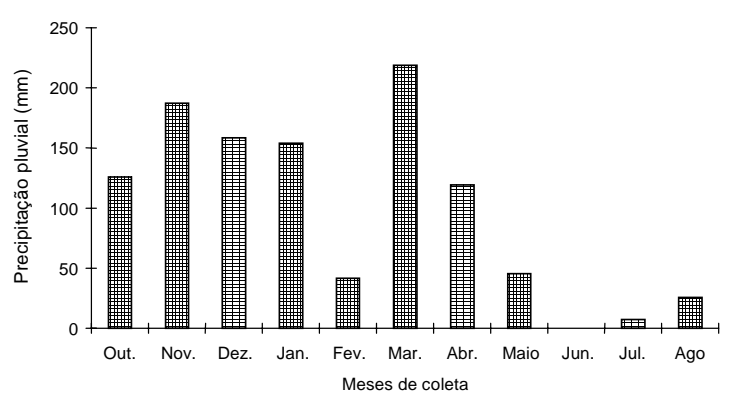

FIG. 1. Dados mensais do total pluviométrico no período de outubro/95 a agosto/96 (Estação Agroclimatológica de Nhumirim).

Para a determinação da biomassa aérea utilizou-se o método de colheita (Frangi et al., 1980; Batmanian, 1983; Neiva, 1990), que consistiu no corte de toda a vegetação herbácea presente em um quadrado de $1 \mathrm{~m}$ x $1 \mathrm{~m}$. Foram realizadas dez coletas mensais por área, cada uma correspondendo a uma parcela. Para cada coleta foram utilizados quadrados anteriormente não cortados. Todo o material vegetal foi cortado rente ao solo e separado os seguintes componentes de interesse: Axonopus purpusii; Mesosetum chaseae; Andropogon bicornis + A. selloanus; outras espécies (constituído de ciperáceas e dicotiledôneas) e material morto. O material resultante da separação de cada quadrado foi acondicionado em saco de papel e mantido em estufa por 48 horas a $65^{\circ} \mathrm{C}$, para obtenção do peso seco. A frequiência foi obtida antes do corte para determinação da biomassa, relacionando-se todas as espécies presentes nos quadrados de $1 \times 1 \mathrm{~m}$, e expressa como a porcentagem de quadrados em que cada espécie ocorreu.

A estimativa da cobertura de solo (\%) foi realizada visualmente em quadrados de $1 \times 1 \mathrm{~m}$, antes do corte da vegetação herbácea, em dez amostragens por área. Em virtude desta variável caracterizar-se por elevada amplitude de variação, os dados foram transformados para a análise estatística em arco seno $\sqrt{\mathrm{p} / 100}$, visando à homogeneidade da variância. Entretanto, a discussão e conclusões são referentes aos dados originais.

O modelo de análise de variância levou em consideração os efeitos de tratamentos e de meses, e suas respectivas interações. Para análise estatística dos dados adotouse o sistema SAS (SAS Institute, 1989).

\section{RESULTADOS E DISCUSSÃO}

\section{Freqüência das espécies}

A queima influenciou a freqüência e o número de espécies presentes na savana gramíneo-lenhosa quando comparada à área testemunha (Tabela 1). As gramíneas apresentaram, em geral, o mesmo número de espécies nas duas áreas, no entanto, as freqüências de Andropogon bicornis, Mesosetum chaseae, Axonopus purpusii, Andropogon selloanus e Paspalum plicatulum foram severamente reduzidas com a queima, evidenciando a menor resistência dessas espécies ao fogo. Segundo Frangi et al. (1980), a freqüência depende da densidade e da distribuição espacial dos indivíduos, por isso é possível que a diminuição das gramíneas esteja associada com mudanças em ambos atributos. BrookmanAmissah et al. (1980) constataram que a época de queimada tem influência na diversidade de espécies, ou seja, queimadas no início da estação seca favorecem a diversidade de espécies e no final da estação seca tendem a reduzir, a longo prazo, o número de espécies.

No grupo de ciperáceas e dicotiledôneas, ao contrário das gramíneas, constatou-se aumento no número e na freqüência das espécies após a queimada, corroborando Aristeguieta \& Medina (1965), Frangi et al. (1980) e Cesar \& Gifford (1981). Segundo Cesar (1980), a queima propicia o aparecimento de maior quantidade de espécies, atribuído por Coutinho (1976) à eliminação da densa cobertura graminosa que provoca o sombreamento do solo, aumentando a competição das plantas e evitando a floração de espécies heliófilas. Embora a freqüência seja um atributo pouco sensível na identificação de mudanças na vegetação, ela pode ser utilizada como critério para avaliar o quanto uma espécie pode variar sua distribuição e abundância depois do fogo (Frangi et al., 1980). Apesar da influência da queima, não foi constatada a eliminação de espécies anteriormente presentes ou o surgimento de novas outras.

\section{Dinâmica da biomassa aérea}

A queima concorreu para diminuir a produção de biomassa aérea total quando comparada à área sem queima (Fig. 2), corroborando diversos autores que estudaram o efeito do fogo em pastagens (Corrêa \& Aronovich, 1979; Cesar, 1980; Batmanian, 1983; Fontaneli \& Jacques, 1988; Neiva,1990; Fontaneli et al., 1994). Embora a biomassa aérea total tenha sido 
TABELA 1. Freqüência de espécies presentes (expressa como a porcentagem de quadrados em que cada espécie ocorreu) em savana gramíneo-lenhosa no Pantanal, com queima (CQ) e sem queima (SQ), no período de outubro/95 a agosto/96.

\begin{tabular}{|c|c|c|c|c|c|c|c|c|c|c|c|c|c|c|c|c|c|c|c|c|c|c|}
\hline \multirow[t]{2}{*}{ Espécie } & \multicolumn{2}{|c|}{ Out. } & \multicolumn{2}{|c|}{ Nov. } & \multicolumn{2}{|c|}{ Dez. } & \multicolumn{2}{|c|}{ Jan. } & \multicolumn{2}{|c|}{ Fev. } & \multicolumn{2}{|c|}{ Mar. } & \multicolumn{2}{|c|}{ Abr. } & \multicolumn{2}{|c|}{ Maio } & \multicolumn{2}{|c|}{ Jun. } & \multicolumn{2}{|c|}{ Jul. } & \multicolumn{2}{|c|}{ Ago. } \\
\hline & SQ & $\mathrm{CQ}$ & SQ & $\mathrm{CQ}$ & SQ & $\mathrm{CQ}$ & SQ & $\mathrm{CQ}$ & SQ & $\mathrm{CQ}$ & SQ & CQ & SQ & $\mathrm{CQ}$ & SQ & $\mathrm{CQ}$ & SQ & $\mathrm{CQ}$ & SQ & $\mathrm{CQ}$ & SQ & $\mathrm{CQ}$ \\
\hline \multicolumn{23}{|l|}{ Gramíneas } \\
\hline Andropogon bicornis $\mathrm{L}$. & 60 & 50 & 50 & 45 & 60 & 20 & 70 & 45 & 70 & 65 & 50 & 35 & 40 & 40 & 30 & 65 & 30 & 60 & 30 & 60 & 70 & 45 \\
\hline Mesosetum chaseae Luces & 100 & 50 & 100 & 55 & 100 & 65 & 90 & 45 & 100 & 30 & 100 & 35 & 90 & 40 & 100 & 65 & 100 & 50 & 90 & 25 & 80 & 40 \\
\hline Axonopus purpusii (Mez) Chase & 100 & 70 & 90 & 85 & 90 & 90 & 100 & 75 & 100 & 85 & 100 & 45 & 90 & 45 & 100 & 90 & 100 & 80 & 100 & 75 & 90 & 80 \\
\hline Andropogon selloanus (Hackel) Hackel & 40 & 35 & 10 & 20 & 80 & 15 & 80 & 30 & 60 & 20 & 50 & 25 & 80 & 25 & 60 & 40 & 70 & 25 & 60 & 35 & 90 & 30 \\
\hline Paspalum plicatulum Michaux & 30 & 10 & 20 & 10 & 30 & 10 & 20 & - & 20 & - & 40 & - & 20 & - & - & - & - & 5 & 30 & 5 & 90 & 5 \\
\hline Setaria geniculata (Lam.) Beauv. & - & 20 & - & 20 & 5 & 55 & 10 & 30 & 20 & 55 & 10 & 10 & 10 & 5 & 10 & 50 & 10 & 20 & - & 40 & 10 & 20 \\
\hline Digitaria fuscescens (Presl) Henr. & - & 10 & - & - & 20 & - & - & - & 10 & 5 & - & - & - & - & - & - & - & 5 & - & - & - & - \\
\hline Panicum laxum Swartz & - & - & - & 30 & - & 35 & 10 & 10 & 10 & 55 & 10 & 20 & 5 & 25 & 10 & 55 & - & 35 & - & 60 & - & 55 \\
\hline Reimarochloa brasiliensis (Spr.) Hitch. & 5 & - & - & 10 & - & 10 & - & 10 & - & 20 & - & 10 & - & 5 & - & 25 & - & - & 5 & 5 & 10 & 5 \\
\hline Reimarochloa acuta (Flueg.) Hitch. & 20 & 20 & - & 20 & - & 20 & - & 25 & - & 25 & - & - & - & - & - & - & - & 5 & - & - & - & - \\
\hline Elyonurus muticus (Spr.) Kunth & 10 & - & - & - & - & - & - & - & - & - & - & - & - & - & - & - & - & - & - & - & - & - \\
\hline Eragrostis bahiensis Schultes & 20 & - & 10 & - & 40 & - & - & - & 10 & - & 20 & 10 & 20 & - & - & 5 & 10 & - & - & - & 10 & - \\
\hline \multicolumn{23}{|l|}{ Ciperáceas } \\
\hline Cyperus sp. & - & 5 & 10 & 40 & 20 & 35 & 30 & 10 & 10 & 15 & 20 & 5 & 20 & 5 & 20 & 30 & - & 5 & 20 & 10 & - & - \\
\hline Eleocharis minima & 60 & 35 & 10 & 20 & - & 60 & 10 & 35 & - & 65 & 20 & 35 & 20 & 40 & 40 & 60 & - & 65 & 10 & 65 & - & 5 \\
\hline Eleocharis acutangula (Roxb.) Steud. & - & 15 & - & - & - & 20 & - & 20 & - & 25 & - & 10 & - & 10 & - & 5 & - & - & 5 & 5 & - & - \\
\hline \multicolumn{23}{|l|}{ Rhynchosphora sp. } \\
\hline Eleocharis sp. & & & 10 & 30 & & & & 20 & & 10 & & & 5 & & 5 & 5 & & 5 & & 10 & & 5 \\
\hline Dicotiledôneas & & & & & & & & & & & & & & & & & & & & & & \\
\hline Waltheria communis St. Hil. & 10 & 10 & - & 30 & 50 & 50 & 20 & 65 & - & 60 & 10 & 35 & 20 & 40 & 20 & 65 & 10 & 30 & 40 & 20 & 10 & 15 \\
\hline Melochia simplex St. Hil. & 10 & 15 & 10 & 35 & 10 & 25 & 20 & 20 & 10 & 20 & - & 5 & 30 & 5 & - & 5 & 20 & 10 & - & 25 & - & 25 \\
\hline Melochia villosa (Mill.) Faw. et R. var. & 30 & - & 30 & - & 40 & - & 40 & - & 60 & - & 40 & - & 20 & 5 & 10 & 10 & 30 & - & 10 & 10 & 20 & - \\
\hline Phillantus amarus Schum. et Thon & - & - & 20 & 40 & 20 & 45 & 20 & 25 & 30 & 25 & 30 & 5 & 40 & 10 & 20 & 20 & 50 & 15 & 5 & 20 & 20 & 15 \\
\hline Sebastiana hispida (Mart.) Pax & 10 & 5 & - & - & - & 10 & - & - & - & - & 5 & - & 10 & - & 5 & 10 & - & 10 & 5 & - & 10 & - \\
\hline Caperonia castaneifolia (L.) St. Hil. & - & 30 & 10 & 45 & - & 60 & - & 35 & - & 50 & - & 15 & - & 15 & - & 30 & - & 25 & - & 30 & - & 10 \\
\hline Croton glandulosus (L.) M. Arg. & - & - & - & - & - & - & - & - & - & 5 & 10 & - & - & - & 5 & 5 & - & - & - & - & - & - \\
\hline Desmodium barbatum (L.) Bth. & 20 & - & - & - & 20 & - & - & - & 50 & - & 20 & - & 10 & 5 & 20 & - & 10 & 10 & 20 & - & 10 & - \\
\hline Aeschynomene sp. & - & 25 & - & - & - & 5 & - & - & - & - & - & - & - & - & 10 & 10 & - & - & - & 10 & - & - \\
\hline Chamaecrista serpens $(\mathrm{L}$.) Greene & - & - & - & - & - & 5 & - & - & 20 & - & 10 & - & - & - & - & 5 & 5 & 10 & 20 & - & 10 & - \\
\hline Mimosa sp. & - & - & - & - & - & - & - & - & - & 5 & 5 & - & 5 & 10 & - & 5 & 5 & - & - & 5 & 5 & - \\
\hline Richardia grandiflora (C. et S.) Steud. & 5 & - & 5 & - & 5 & - & 30 & - & - & - & - & - & 10 & - & 10 & - & - & - & 10 & - & - & - \\
\hline Diodia kuntzei Schum. & 30 & 45 & - & 40 & - & 55 & - & 55 & 10 & 60 & 10 & 15 & 10 & 20 & 30 & 35 & - & 30 & - & 35 & - & - \\
\hline Borreria verticillata (L.) Meyer & - & - & 10 & - & 10 & - & - & - & 30 & - & 5 & - & 30 & - & 40 & 5 & 40 & 5 & - & - & 10 & - \\
\hline Sida cerradoensis Krap. & - & 10 & - & - & - & - & - & - & - & - & - & - & 5 & 5 & - & - & - & 5 & 10 & 5 & - & 5 \\
\hline Hyptis lappacea Bentham & - & 10 & 10 & 35 & 30 & 50 & - & 65 & 20 & 65 & 10 & 10 & 10 & 10 & 40 & 40 & - & 15 & 10 & 35 & - & - \\
\hline Hyptis crenata Pohl & - & 5 & - & - & 10 & 10 & - & - & - & 5 & - & 5 & - & - & 5 & 10 & - & - & - & - & - & 5 \\
\hline Ludwigia sp. & 20 & - & 10 & 5 & - & - & 20 & 5 & 20 & 10 & 10 & 15 & 5 & 10 & 10 & 10 & 20 & 10 & - & 10 & 5 & - \\
\hline Ophioglossum crotalophoroides Walt. & - & 15 & - & 40 & 10 & 35 & - & 20 & 20 & - & 30 & - & 20 & - & 10 & 5 & - & 10 & 10 & 5 & - & 5 \\
\hline Tibouchina sp. & - & - & - & - & - & - & - & 5 & - & 15 & - & 5 & 5 & - & - & - & 10 & - & - & 5 & - & - \\
\hline Bacopa myriophylloides (Benth.) Wettst. & - & 5 & - & 5 & - & 5 & - & 10 & - & 15 & - & - & - & - & - & 15 & - & - & - & 10 & - & - \\
\hline Polygola sp. & - & 10 & - & - & - & - & 40 & - & 40 & 20 & 60 & 20 & 60 & 25 & 20 & 5 & - & 20 & 5 & 15 & 5 & - \\
\hline Ageratum conyzoides $\mathrm{L}$. & - & - & - & 20 & - & - & - & - & - & - & 5 & - & 5 & - & - & - & 5 & - & - & - & - & - \\
\hline Número de espécies & 18 & 23 & 17 & 22 & 19 & 24 & 16 & 23 & 21 & 26 & 26 & 22 & 29 & 23 & 24 & 31 & 18 & 26 & 20 & 27 & 19 & 18 \\
\hline
\end{tabular}


inferior após a queima, sua tendência de incremento foi semelhante nas duas áreas, ou seja, aumento até o mês de fevereiro, período caracterizado por distribuição uniforme de chuvas (Fig. 1) e estabilização nos meses de baixa precipitação. Segundo Brâncio et al. (1997), em termos de variação, o aumento relativo na disponibilidade de matéria seca em áreas sem queima é menor quando comparado a áreas queimadas, sugerindo assim que a maior disponibilidade de matéria seca na área sem queima é, em parte, explicada pelo efeito residual do material proveniente do crescimento em anos anteriores. A redução de biomassa observada nos meses de março e abril nas duas áreas pode ser atribuída à lâmina d'água que permaneceu no campo por alguns dias cobrindo parte das plantas, ocasionada pela elevada precipitação ocorrida nesses dois meses. A área com queima apresentou maior redução relativa de biomassa viva no mês de abril, sugerindo que a vegetação herbácea que se encontrava em fase de intensa rebrota foi mais prejudicada.

A produção de biomassa morta na área sem queima foi expressiva, representando aproximadamente
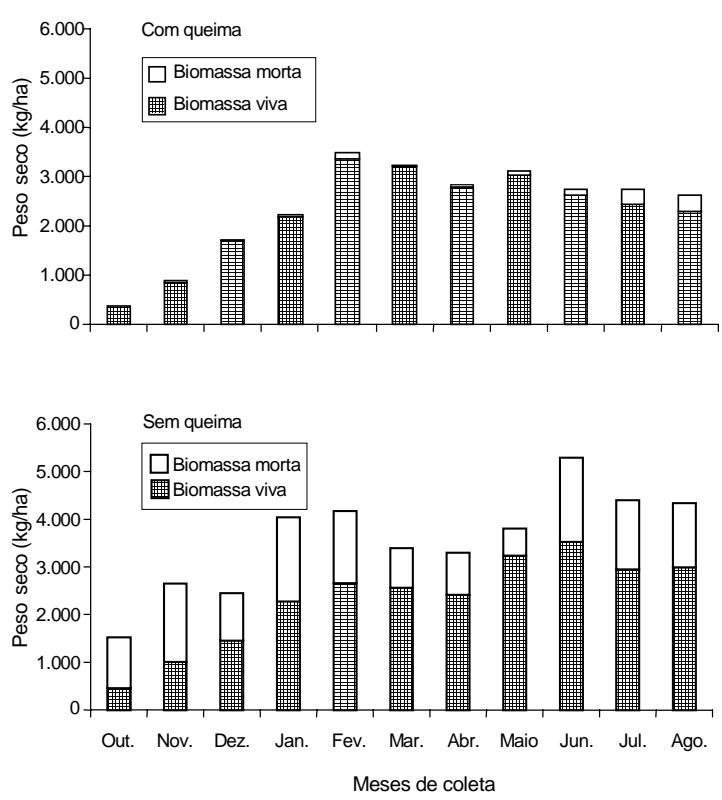

FIG. 2. Variação da biomassa aérea total em savana gramíneo-lenhosa no Pantanal, com e sem queima no período de outubro/95 a agosto/96.
$37 \%$ da biomassa aérea total. Na área com queima a biomassa morta praticamente não foi constatada, somente após transcorridos dez meses, em julho e agosto, foi verificada pequena produção, representando aproximadamente $4 \%$ da biomassa aérea total, e apenas $25 \%$ da obtida na área sem queima. Segundo Fontaneli et al. (1994), a cobertura morta é importante para a conservação e manutenção da produtividade das pastagens. Os mesmos autores destacam ainda que como o material morto é o componente de maior participação na composição botânica, atenção especial deve ser dada à sua importância na manutenção das condições físicas, químicas e biológicas da pastagem.

A queima condicionou um comportamento diferenciado da biomassa aérea dos componentes estudados quando comparada à área sem queima (Fig. 3). As biomassas de Mesosetum chaseae e Andropogon
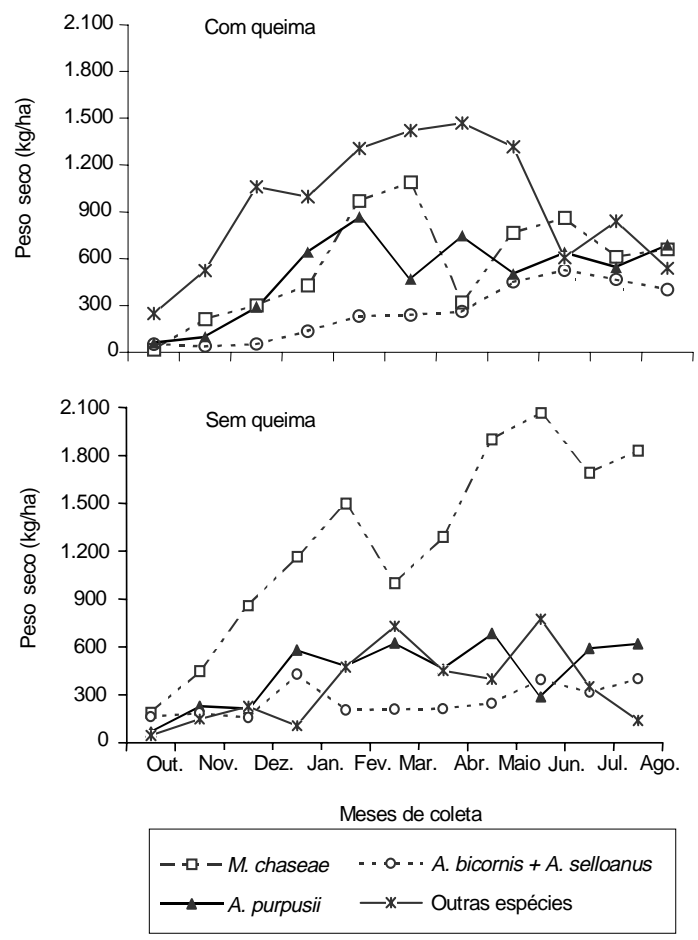

FIG. 3. Variação da biomassa aérea de Axonopus purpusii, Mesosetum chaseae, Andropogon bicornis + A. selloanus e outras espécies em savana gramíneo-lenhosa no Pantanal, com e sem queima, no período de outubro/95 a agosto/96. 
bicornis + A. selloanus foram prejudicadas pela quei$\mathrm{ma}$, pois as produções foram inferiores na área com queima, indicando, provavelmente que essas espécies foram mais afetadas pelo fogo, embora a tendência de incremento de biomassa nos primeiros meses tenha sido semelhante para estas espécies nas duas áreas. Segundo Klink \& Solbrig (1996), o fogo pode afetar a sobrevivência das partes aéreas, a germinação após a queimada, a regeneração vegetativa, a reprodução sexuada e a mortalidade das plantas. A participação de Mesosetum chaseae e Andropogon bicornis + A. selloanus na biomassa aérea total da área sem queima representou aproximadamente $34 \%$ e $9 \%$, respectivamente, enquanto na área com queima $22 \%$ e $11 \%$, respectivamente. A participação da biomassa de Andropogon bicornis + A. selloanus aumentou na área com queima, o que se deveu à redução da biomassa aérea total e não propriamente à elevação da biomassa destas espécies.

Por sua vez, Axonopus purpusii e o componente outras espécies apresentaram incremento em suas biomassas após a queimada. As espécies desses componentes apresentaram uma rápida rebrota nos meses subseqüentes à queima, em virtude, provavelmente, do melhor aproveitamento dos nutrientes provenientes das cinzas, da baixa competição interespecífica por luz e regular precipitação pluvial ocorrida no período (Fig. 1). Budowski (1956) relata que as espécies resistentes ao fogo podem ser favorecidas nas primeiras queimas, no entanto, após repetidas queimadas podem ser prejudicadas. A participação de Axonopus purpusii e do componente outras espécies na biomassa aérea total da área sem queima foi de aproximadamente $12 \%$ e $9 \%$, respectivamente, enquanto na área com queima foi de aproximadamente $20 \%$ e $44 \%$, respectivamente. O componente outras espécies merece destaque em virtude da expressiva diferença verificada entre as duas áreas, sendo que na área com queima sua biomassa foi a mais representativa. Esse componente foi constituído principalmente por dicotiledôneas, que tiveram número e frequiência aumentados após o fogo, contribuindo para o aumento da biomassa aérea.

\section{Cobertura do solo}

A rebrota após a queima ocorreu de forma rápida e intensa, porém a cobertura do solo foi inferior ao da área sem queima nos três primeiros meses. Somente em abril as duas áreas foram semelhantes, sendo constatada uma cobertura de aproximadamente $80 \%$ (Fig. 4). Resultados similares foram apresentados por Corrêa \& Aronovich (1979) e Fontaneli \& Jacques (1988). Entretanto, Fontaneli et al. (1994) verificaram que a queima no final do inverno diminui a cobertura do solo e demora até seis meses para estar em $95 \%$.

No primeiro mês após a queima, a cobertura do solo foi de aproximadamente $40 \%$. Como os solos do Pantanal são predominantemente arenosos e com baixa retenção de umidade, provavelmente a exposição do solo aos raios solares possa ter reduzido ainda mais os teores de umidade, aumentando assim a vulnerabilidade das plantas à seca, corroborando Fontaneli \& Jacques (1988).

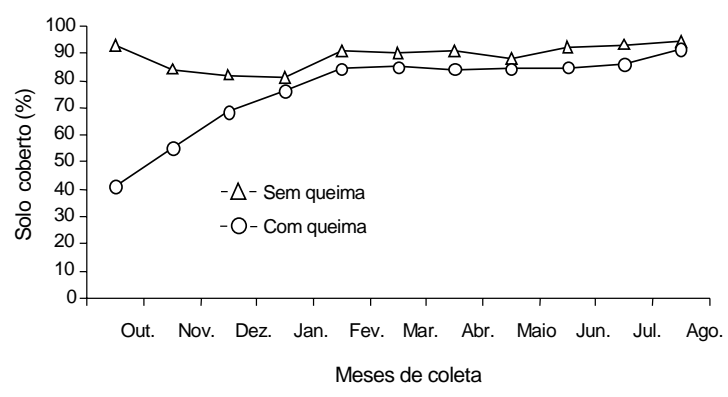

FIG. 4. Variação da cobertura do solo em savana gramíneo-lenhosa no Pantanal, com e sem queima, no período de outubro/95 a agosto/96.

\section{CONCLUSÕES}

1. A queima reduz a freqüência das gramíneas que predominam na savana gramíneo-lenhosa e aumenta o número de espécies de dicotiledôneas e ciperáceas.

2. A queima condiciona menor produção de biomassa aérea total, sendo a biomassa morta a mais prejudicada, uma vez que mesmo 11 meses após a queima a produção é ainda muito baixa, representando aproximadamente $25 \%$ da obtida na área sem queima. 
3. O solo permanece excessivamente exposto após a queima e somente depois de quatro meses assemelha-se às condições da área sem queima.

\section{REFERÊNCIAS}

ABDON, M.M.; SILVA, J. dos S.V.da; POTT, V.J.; POTT, A.; SILVA, M.P. Utilização de dados analógicos do LANDSAT-TM na discriminação da vegetação de parte da sub-região da Nhecolândia no Pantanal. Pesquisa Agropecuária Brasileira, Brasília, v.33, p.1799-1813, out. 1998. Número especial.

ARISTEGUIETA, L.; MEDINA, E. Protección y quema de la sabana llanera. Boletín de la Sociedad Venezolana de Ciencias Naturales, Caracas, v.109, p.129-139, 1965.

BATMANIAN, G.J. Efeitos do fogo sobre a produção primária e a acumulação de nutrientes do estrato rasteiro de um cerrado. Brasília : UnB, 1983. 78p. Dissertação de Mestrado.

BLYDENSTEIN, J. Cambios en la vegetación después de la protección contra el fuego. Parte I. El aumento anual en material vegetal en varios sitios quemados y no quemados en la Estación Biológica. Boletín de la Sociedad Venezolana de Ciencias Naturales, Caracas, v.103, p.233-238, 1963.

BOLETIM AGROMETEOROLÓGICO: 1986-1996 (Fazenda Nhumirim). Corumbá : Embrapa-CPAP, v.3, 1997. 81p.

BRÂNCIO, P.A.; NASCIMENTO JÚNIOR, D.; REGAZZI, A.J.; MORAES, E.A.; LEITE, G.G. Avaliação de pastagem nativa dos cerrados submetida à queima anual. 1. Composição botânica da dieta de bovinos. Revista Brasileira de Zootecnia, Viçosa, v.26, n.3, p.429-437, 1997.

BROOKMAN-AMISSAH, J.; HALL, J.B.; SWAINE, M.D.; ATTAKORAH, J.Y. A re-assessment of fire protection experiment in North-Eastern Ghana savanna. Journal of Applied Ecology, Oxford, v.17, n.1, p.85-99, 1980.

BUDOWSKI, G. Tropical savannas: a sequence of forest felling and repeated burnings. Turrialba, San José, v.6, n.1/2, p.23-33, 1956.

CADAVID GARCÍA, E.A. O clima no Pantanal MatoGrossense. Corumbá : Embrapa-CPAP, 1984. 39p. (Embrapa-CPAP. Circular Técnica,14).

CESAR, H.L. Efeitos da queima e corte sobre a vegetação de um campo sujo na fazenda Água Limpa, Distrito Federal. Brasília : UnB, 1980. 59p. Dissertação de Mestrado.
CESAR, H.L.; GIFFORD, D.R. Flora indicadora de fogo e corte em um campo do Distrito Federal. In: CONGRESSO NACIONAL DE BOTÂNICA, 32., 1981, Teresina. Anais. Teresina : Sociedade Brasileira de Botânica, 1981. p.201-206.

CORRÊA, A.N.S.; ARONOVICH, S. Influência da queima periódica sobre a vegetação e sobre a fertilidade dos terrenos de pastagens. Revista Brasileira de Zootecnia, Viçosa, v.8, n.2, p.332-347, 1979.

COUTINHO, L.M. Contribuição ao conhecimento do papel ecológico das queimadas na floração de espécies do cerrado. São Paulo : USP, 1976. 173p. Tese de Livre-Docência.

COUTINHO, L.M.; DE VUONO, Y.S.; LOUSA, J.S. Aspectos ecológicos do fogo no cerrado. IV. A época da queimada e a produtividade primária líquida-epigéia do estrato herbáceo subarbustivo. Revista Brasileira de Botânica, São Paulo, v.5, p.37-41, 1982.

EMBRAPA. Centro de Pesquisa Agropecuária do Pantanal (Corumbá, MS). Plano diretor do Centro de Pesquisa Agropecuária do Pantanal-CPAP. Brasília, 1993. 41p.

FONTANELI, R.S.; JACQUES, A.V.A. Melhoramento de pastagem natural: ceifa, queima, diferimento e adubação. Revista Brasileira de Zootecnia, Viçosa, v.17, n.2, p.180-194, 1988.

FONTANELI, R.S.; JACQUES, A.V.A.; HENRICH, C.; OERLECKE, D.; SCHUSTER, I.; FONTANELI, R.S. Efeito da ceifa, da queima, do diferimento e da adubação sobre uma pastagem natural. Revista Brasileira de Zootecnia, Viçosa, v.23, n.5, p.719-729, 1994.

FRANGI, J.L.; RONCO, M.G.; SANCHES, N.E.; VICARI, R.L.; ROVETTA, G.S. Efecto del fuego sobre la composición y dinámica de la biomasa de un pastizal de Sierra de la Ventana (Bs. As., Argentina). Darwiniana, Buenos Aires, v.22, n.4, p.565-585, 1980.

KLINK, C.A.; SOLBRIG, O.T. Efeito do fogo na biodiversidade de plantas do cerrado. In: SARMIENTO, G.; CABIDO, M. (Ed.). Biodiversidad y funcionamiento de pastizales y sabanas en América Latina. Mérida, Venezuela : CYTED y CIELAT, 1996. p.231-244.

MATTOS, J.C.A. de. A influência do fogo na vegetação e o seu uso no estabelecimento e manejo de pastagens. Zootecnia, Nova Odessa, v.8, n.4, p.45-58, 1970.

NEIVA, J.N.M. Crescimento e valor nutritivo de pastagens nativas submetidas ou não ao tratamento de queima. Lavras : ESAL, 1990. 97p. Dissertação de Mestrado. 
PEREIRA, J.; PERES, J.R. Manejo de matéria orgânica. In: GOEDERT, W.J. (Ed.). Solos dos cerrados: tecnologia e estratégias de manejo. São Paulo : Embrapa-CPAC/Nobel, 1985. p.261-284.

POTT, A. Pastagens das sub-regiões dos Paiaguás e da Nhecolândia do Pantanal Mato-Grossense. Corumbá : Embrapa-UEPAE de Corumbá, 1982.49p. (Embrapa-UEPAE de Corumbá. Circular Técnica, 10).

SAN JOSÉ, J.J.; MEDINA, E. Effect of fire on organic matter production and water balance in a tropical savanna. In: GOLLEY, F.B.; MEDINA, E. (Ed.). Tropical ecological systems: trends in terrestrial and aquatic research. New York : Springer, 1975. p.251-264.(Ecological Studies. Analysis and Synthesis, 11).

SAS INSTITUTE (Cary, Estados Unidos). SAS/STAT user's guide: version 6. 4.ed. Cary, 1989. v.2.

VALENTINE, J.F. Grazing management. San Diego, California : Academic, 1990. 533p. 